\title{
Arbor
}

\section{Cartas botánicas en recuerdo de Eladio Viñuela}

\section{Francisco García Olmedo}

Arbor CLXVIII, 662 (Febrero 2001), 209-222 pp.

Situarse a popa y contemplar la efimera estela Invita a anudar el equipaje para el olvido

Y también a no llorar lo que no se ganó en el empeño

\section{A Margarita Salas}

\section{1}

Al recibir la invitación de escribir un artículo sobre el desarrollo de la genética molecular de las plantas superiores en España, acepté sin dudarlo, antes de percatarme de la dificultad del encargo. Se trataba de escribir en memoria de Eladio, mi siempre añorado amigo, y era natural que yo estuviera dispuesto a contribuir a tal homenaje. Esa circunstancia tal vez ocultó el problema de cubrir un área de investigación tan amplia y tan diversa en un tiempo y un espacio tan limitados. A los que practicamos investigación de secano nos tenían bastante olvidados y ahora, cuando nos invitan, tenemos el reflejo condicionado de aceptar en el acto, sin plena consciencia de a qué nos comprometemos. Lo que sigue es una serie de recuerdos, notas y reflexiones relacionadas con el mencionado tema, escritas mientras buscaba cómo evitar mi fracaso. Las he plasmado en forma epistolar. Espero que me las acepten en sustitución del producto genuino.

Eladio sabía en qué consistía y respetaba la investigación de «año y vez». Reconocía que, a igualdad de ingenio y esfuerzo, los resultados tendían a ser menos jugosos, pero no menos respetables o útiles. Las 


\section{Francisco García Olmedo}

investigaciones sobre las plantas en nuestro país fueron siempre consideradas de secano, si se juzga por la magnitud de los apoyos recibidos. De aquí que, cuando uno ha cedido ya el testigo, sea una satisfacción observar el vigor actual de estos estudios entre nosotros.

Para empezar mi aventura, he desempolvado la edición española de la «Química Biológica» de H. R. Mahler y E. B. Cordes (Omega, 1971), uno de los libros que yo utilicé en tiempos como apoyo docente. Después de tanto tiempo no me falla la memoria: el texto tiene referencias bibliográficas al final de cada capítulo. Sólo tres de éstas corresponden a trabajo hecho en España y reflejado en revistas internacionales. Las tres, publicadas entre 1963 y 1965, llevan como autores a Eladio Viñuela, Margarita Salas y Alberto Sols, en distintos órdenes. En relación con las plantas sólo aparece Manuel Losada, todavía como coautor de trabajos del grupo de D. I. Arnon, aunque sí encuentro cita de sus primeros trabajos en España cuando consulto otro libro de la misma época, Plant Biochemistry, de J. Bonner y J. E. Varner (Academic Press, 1965). Se trata de un trabajo de 1965 - cofirmado con A. Paneque, J. M. Ramírez y F. F. del Campo- sobre la reducción del nitrito en la espinaca, un trabajo de los de «empujar electrones», como alguien los llamaba entonces.

Estas investigaciones, que se ocupaban de la incidencia de la fotosíntesis sobre el metabolismo del nitrógeno en las plantas, eran de absoluta vanguardia en la época y dieron lugar a un poderoso venero que fluyó hacia cotas cada vez más reduccionistas, desde las espinacas a las algas y los microorganismos. Y es que, bien pensado, para algunas características distintivas de una planta superior - la pared celular o la capacidad fotosintética- siempre se encuentran modelos más sencillos donde estudiarlas. La escuela de Losada ha brillado en los estudios sobre el metabolismo del nitrógeno durante estas últimas décadas y ha confluido con otras tradiciones centradas en el lado bacteriano de la fijación simbiótica del nitrógeno para ocupar una parcela bien definida en la investigación biológica española.

Si esta tradición se desarrollaba por cauces estrictamente bioquímicos, ajenos a la herramienta genética, algo similar ocurría con la mejora vegetal, que se atenía a unos métodos genéticos bien depurados, sin necesidad de descender a lo molecular. Esta tradición en España se remonta a la década de los años treinta, cuando Cruz Gallástegui introdujo los maíces híbridos, y ha sido dominada por la figura de Enrique Sanchez-Monge. Dicho sea de paso, Gallástegui, que era veterinario, fue mentor de mi admirado Miguel Odriozola, ingeniero agrónomo cuyas investigaciones sobre la genética de animales superiores 


\section{Cartas botánicas en recuerdo de Eladio Viñuela}

-el caballo, el toro de lidia, el cerdo- merecieron admiración y respeto por parte de figuras como T. Dobzhansky, Sewall Wright o R. A. Fisher. Yo relacioné a Eladio con Odriozola y atesoro en mi memoria - como creo que lo harás tú, Margarita- las numerosas, largas, espléndidas veladas que pasamos juntos.

Sanchez-Monge inició su carrera como investigador en la Estación Experimental de Aula Dei, donde colaboró con Joe Hin Tjio, el mismo que unos años más tarde determinaría de forma definitiva el número de cromosomas del ser humano. Juntos obtuvieron el Triticale hexaploide, anfiploide de trigo tetraploide y centeno, que representa la única especie vegetal obtenida experimentalmente que se cultiva a una escala de miles de hectáreas. De mayor transcendencia para nuestro país fue la selección por Sanchez-Monge de la variedad de cebada «Albacete» que, cuatro décadas después, sigue siendo la más sembrada en el secano español y que se cultiva también en el norte de África.

En Aula Dei se inició también una tradición de investigaciones sobre citogenética vegetal por el mismo Sanchez-Monge y por su sucesor J. R. Lacadena. En este contexto, también debe mencionarse a Manuel Alonso Peña, agrónomo que fue desterrado a Cuenca por republicano, donde con el tiempo llegaría a desempeñar la jefatura agronómica provincial. A pesar de sus ideas, discutía de Teología con el famoso Monseñor Guerra Campos, obispo integrista donde los hubiera, y, los días de fiesta, enseñaba la catedral a los turistas. A menudo, éstos confundían su capa española con la indumentaria eclesiástica y llegaban a besarle la mano en señal de respeto. Era un excelente botánico y genético formado en Alemania - había coincidido con Odriozola en Berlín- y subrepticiamente hacía experimentos en un solar del casco urbano, hoy construido. Él nos cedió un rico material genético sobre el que aún hoy se investiga en nuestro laboratorio.

Éstas eran mis referencias de partida; éste era el panorama que se divisaba desde la peculiar institución en la que me tocó iniciar mi carrera científica, esencialmente como autodidacta. Del clima alienado que imperaba en ella me salvaron dos personas admirables: el ya mencionado Enrique Sanchez-Monge y mi tutor de tesis, Juan Santa María, especialista en levaduras de prestigio internacional, quien enseñó Bioquímica con un carisma inigualable a muchas generaciones de agrónomos. De mis vivencias hablaré en la siguiente epístola, no porque me parezcan más importantes que las de otros - hace tiempo que estoy preparado para el olvido- sino sencillamente porque son las que conozco mejor. 
Yo quería ser bioquímico, pero no tenía acceso al equipo más indispensable, a excepción de un extendedor de placas cromatográficas y de un colorímetro, y esta limitación me llevó a intentar combinar la bioquímica con la genética, a dejar que fueran las plantas las que hicieran los experimentos. El primer gen que caractericé resultó ser responsable de la esterificación de esteroles libres en las fases finales del desarrollo del grano de trigo. Viendo su distribución en especies próximas, llegué a la conclusión de que en la evolución de éstas ocurría un silenciamiento génico en loci redundantes. Entre los libros que con frecuencia me regalaba Eladio estuvo, un tiempo después, uno de Susumu Ohno, en el que hacía un magnífico tratamiento del significado de la duplicación génica en la evolución. Las mencionadas observaciones, que se extendieron a más genes, así como otras similares que se hicieron más tarde en especies de peces ciprínidos, tuvieron sus efímeros momentos de reconocimiento y están hoy justamente olvidadas, aunque el fenómeno ha vuelto a suscitar interés - véase si no una reseña y un trabajo recientemente aparecido en Science- y se ha confirmado su importancia de forma más directa al secuenciar el ADN de diversas especies. No merecerían mención alguna si no fuera por evocar las circunstancias en que se hicieron.

Hacía años que la institución había dejado de suscribirse a las escasas revistas de la especialidad que habían poblado su biblioteca por un tiempo. Parece que, un buen día, el investigador que las demandaba había abandonado su laboratorio por la frontera, sin aviso o trámite alguno, y, en consecuencia, la dirección había cancelado las suscripciones. Se rumoreaba que Santa María estaba suscrito personalmente a algunas de las revistas más importantes, que recibía en su domicilio, mientras Sanchez-Monge, que dirigía un instituto, tenía una persona dedicada casi con exclusividad a pedir y clasificar separatas. En su inmensa colección, a la que tenía generoso acceso, navegaba yo con frecuencia, buscando un norte a mis experimentos.

El instituto en el que yo trabajaba se dedicaba oficialmente a los trigos, pero allí no parecía que se hiciera genética de especie alguna. En cambio, en el que oficialmente se debía mejorar el maíz, se investigaba muy activamente en trigo híbrido bajo la dirección de Sanchez-Monge. El castrado del trigo a mano se asemeja a la práctica del yoga, se requiere la misma paciencia y el mismo estado de ánimo: con unas pinzas se eliminan las anteras de cada una de las espiguillas que componen una espiga, la mente vuela hasta las nubes y uno tiene la sensación de 


\section{Cartas botánicas en recuerdo de Eladio Viñuela}

levitar. Recuerdo ese tiempo - en que, con su consentimiento y apoyo, parasité el programa de Sanchez-Monge- como el que más próximo estuve a la experiencia mística.

Poco antes de completar el estudio del primer gen, encontré en la colección antes aludida una separata de la revista Nature en la que se describía un gen de trigo y la adopté no sólo como "guía de viaje» sino como manual de estilo: la seguí casi al pie de la letra para escribir mi trabajo. Cuando lo tuve listo, se lo enseñé a Sanchez-Monge y a Santa María, quienes me animaron a enviarlo a la mencionada revista, donde ambos habían publicado más de una vez. Creo recordar que fue Santa María quien me dio la dirección editorial, ya que yo no conocía biblioteca alguna que me diera acceso a la revista en cuestión.

Después de más de treinta años, éste sigue siendo el único trabajo que me ha sido aceptado sin corrección u objeción alguna, así como el único del que he sido autor en solitario. Años más tarde, en una recepción en New Dehli — después de pasear por el jardín de la residencia de Indira Ghandi- el presidente de la Academia de Ciencias de la India, cuya tarjeta de visita enumeraba medio centenar de honores por ambas caras, me presentó a Sir Ralph Riley, entonces asesor científico del gobierno británico, y en la conversación que siguió saqué a relucir la historia de mi exitoso plagio literario, que no científico. $\mathrm{Me}$ quedé sorprendido cuando mi interlocutor dio muestras de conocerlo muy bien. Según declaró, no sólo era el autor de mi "guía» sino que había sido el evaluador de mi trabajo en nombre de Nature. Hace muy poco, visitando una biblioteca, me entretuve en ver por primera vez mi trabajo en las páginas de la revista - sólo lo conocía en separata- y pude comprobar que entonces, como ahora, los trabajos con domicilio español en las páginas de dicha revista distaban mucho de formar legión.

Creo recordar que ese trabajo fue el primero que presenté a una reunión de la Sociedad Española de Bioquímica. Ésta fue también la primera ocasión en que fui presentado a Alberto Sols, luego lo sería muchas veces a lo largo de los años. Contigo y con Eladio, sus discípulos, no me atrevería a hablar hasta un tiempo después. Por entonces encarnábais para mí a unos seres superiores que parecían saber de donde venían y adonde iban.

Con la obtención de una cátedra en 1970 mejoró mi status social pero no mi situación real. El nuevo destino se reducía a poco más 
que un aulario y unos laboratorios de prácticas apenas dotados, excepción hecha de una enciclopedia. Los pocos profesores que investigaban, lo hacían en otros organismos. No existían despachos, excepto los de dirección, y resultó insólito que yo solicitara uno, al tiempo que la dedicación exclusiva. Lo primero llegó antes que lo segundo. Un dato cuantitativo retrata la situación mejor que cualquier descripción: el edificio consumía entonces mil veces menos energía que en la actualidad.

La tarea a realizar estaba muy clara; no así los modelos a emular. Nuestra experiencia americana - la de Pilar Carbonero y la míaera de muy difícil traducción a las precarias condiciones que nos tocaron en suerte y resultó inevitable que el naciente Centro de Biología Molecular (CBM) acabara convirtiéndose en nuestra referencia. Mi trato asiduo contigo y con Eladio empezó por aquellos tiempos en que se gestó la idea del CBM y recuerdo bien muchas anécdotas que contradicen la historia oficial que se ha impuesto, aunque no es éste el lugar de desmentirla. El CBM era un modelo utópico y fuera de alcance, aunque visitable. No nos hubiera servido de nada - no podíamos soñar siquiera con introducir en nuestro entorno las más modestas de sus características- a no ser por vuestra amistad y respeto.

Todos los problemas que abordamos en la década de los 70 lo fueron con medios en extremo rudimentarios, que se reducían en esencia a unos aparatos para electoforesis bidimensional que nos fabricábamos, un invernadero en desuso y unos cientos de metros cuadrados de suelo laborable. La investigación experimental ha sido siempre el arte de lo posible $\mathrm{y}$, en nuestro caso, los medios limitaban seriamente a la imaginación. Aunque, así descrito, el panorama pueda parecer desolado, existían compensaciones - extinguidas en las circunstancias actualesque nos permitían sobrevivir y no ser del todo infelices. Por un lado estaba el agudo sentido de progreso casi heroico que nos embargaba siempre que conseguíamos cualquier mejora, aunque fuera nimia. Por otro, el placer y la celebración que entonces acompañaban a la aceptación de cualquier trabajo en Genetics o en los Proceedings of the National Academy of Sciences.

Entre los temas que abordamos en esa década pueden mencionarse los siguientes: péptidos vegetales activos frente a patógenos de las plantas; péptidos vegetales activos frente a insectos; mapas genéticos y uso de marcadores en la transferencia de genes de resistencia desde especies silvestres a cultivadas; silenciamiento de genes duplicados; y variación genética de la relación dosis génica/cantidad de proteína, incluido el fenómeno de compensación de dosis génica en plantas. Con 


\section{Cartas botánicas en recuerdo de Eladio Viñuela}

todas las salvedades, hoy describiríamos como proteo-genómica la aproximación experimental que dominaba en estos estudios.

Hacia el final de la década empezó a resultar evidente que se estaban desarrollando nuevas formas mucho más adecuadas para enfrentar este tipo de investigación y que no tendríamos más opción que reconvertirnos si queríamos seguir adelante. Éramos reacios -como recordarás, Margarita- a empezar de nuevo y nos daban miedo los problemas prácticos de obtener un equipamiento sofisticado del que carecíamos por completo y para el que nos iba a costar trabajo obtener los recursos necesarios.

Como también recordarás, nos refugiamos en el CBM durante unos meses antes de emprender la nueva aventura. Volver a empezar -a la edad que muchos terminan su periodo álgido como investigadoresproduce sentimientos encontrados, una sensación de rejuvenecimiento junto a la de no estar a la altura de las circunstancias. Pilar se involucró en el proyecto del virus de la peste porcina africana y luego pasaría un tiempo en Cold Spring Harbor, donde, entre otras aventuras, conoció a su ídolo Barbara McClintock. Yo fui usuario del despacho de Ochoa, donde pasé largas horas leyendo e incluso durmiendo la siesta en su amplio sofá, y aprendí los arcanos de la traducción in vitro con José Manuel Sierra, para luego irme a Gante, donde aprendería a transformar plantas antes de que se hubiera logrado la expresión de ningún gen foráneo en ellas.

En 1983, al tiempo que publicamos en EMBO J. los primeros resultados de nuestra nueva etapa, nos aceptaron en Nature los últimos de la anterior, que se referían precisamente a la transferencia - mediante trucos in planta- de un gen de resistencia al «mal de pie» desde una especie silvestre al trigo. Dicha enfermedad, causada por el hongo Pseudocercosporella herpotricoides, causa graves pérdidas de cosecha en muchas regiones trigueras del mundo. El gen que caracterizamos sigue siendo el único que confiere tal resistencia y se usa en muchos programas de mejora. La publicación fue reseñada en diversas revistas de divulgación y aún hoy se suele aludir a ella sin citar a los autores, tal como hacía una reciente editorial de Nature. Fue un fin de fiesta digno.

Como puede verse, al principio de la década de los 80 , no nos cupo más que cambiar deprisa para poder seguir en el mismo tajo. 
Y así desembocamos en la ingeniería genética de plantas. Por esas fechas hubo además una gran afluencia de investigadores procedentes de otras áreas hacia lo vegetal. Dentro de esta corriente se identifica el grupo del CSIC Barcelona, que empieza a publicar sobre proteínas de endospermo de maíz hacia 1984. Entre los autores de esos primeros trabajos -J. Palau, P. Puigdomènech, M. Pagés, S. Prat, M. D.Ludevid, J. A. Martínez Izquierdo, J. Cortadas (qepd)_ estaban los principales responsables del vigor actual que estos estudios han alcanzado en el CID-CSIC de Barcelona bajo la gestión de Pere Puigdomenech: de las proteínas de reserva a la embriología vegetal, la respuesta a la sequía, la genómica y la cartografía genética, los mecanismos de acción hormonal y muchas otras cuestiones.

En nuestro entorno inmediato, lo que nos involucró inicialmente a dos investigadores al principio de la década, acabó implicando a casi un centenar de personas al final de ella, cuando en 1987 se consolidó lo que luego se llamaría Departamento de Biotecnología de la Universidad Politécnica de Madrid. La ingeniería genética era ya herramienta común en varios de los cinco departamentos que se fusionaron en el nuevo: Bioquímica y Biología Molecular de la Escuela de Ingenieros de Montes, Bioquímica y Biología Molecular, Microbiología, Genética y Mejora Vegetal y Patología Vegetal de la de Ingenieros Agrónomos.

Al final de la década, el departamento estaba razonablemente equipado para el trabajo que realizábamos, aunque muy por debajo de otros laboratorios nacionales. Habíamos olvidado ya los tiempos en que reciclábamos los tubos Eppendorf y los tips de pipeta del CBM y teníamos que regenerar las plantas transformadas sobre los bancos del laboratorio, sin control de luz, humedad o temperatura. Además, nos parecía mentira que hubiéramos empezado a vender tecnología en el mercado internacional (primera cesión de derechos de patente y licencia exclusiva en 1989) o que en nuestro nuevo departamento pudieran convivir, en un momento dado, investigadores de Estados Unidos, varios países hispano-americanos, Australia, Reino Unido, Holanda, Rusia, Suiza, Italia y el Magreb.

A mediados de la década se inició el proyecto del Centro Nacional de Biotecnología (CNB), que incluía una división de plantas, cuya dirección durante un periodo fundacional (1986-1993) recayó en Pilar Carbonero, para luego ser sucedida por Javier Paz-Ares. En los laboratorios verdes del $\mathrm{CNB}$, en los que trabajan unas 60 personas, se investiga sobre factores transcripcionales, estrés abiótico, interacción patógeno-planta, virología, biología del desarrollo y genómica, entre otras líneas. 


\section{Cartas botánicas en recuerdo de Eladio Viñuela}

El último núcleo numéricamente importante de genética molecular de plantas se inaugura en Valencia en 1995. Se trata del Instituto de Biología Molecular y Celular de Plantas (IBMCP), que resulta de la confluencia intelectual de Vicente Conejero y José Pío Beltrán, junto con la cooperación institucional entre la Universidad Politécnica de Valencia y el CSIC. Los estudios sobre interacción patógeno-planta del primero y los de carácter fisiológico del segundo habían desembocado en un abordaje de genética molecular al principio de la década de los 90. De la vitalidad del IBMCP da una idea el hecho de que se haya pasado de 75 personas en 1994 a 175 personas en la actualidad. La lista de líneas de trabajo de este instituto es muy extensa y cubre prácticamente todas las vertientes actuales de la especialidad.

El panorama de la genética molecular de plantas en nuestro país no se restringe a los centros antes mencionados sino que afortunadamente abarca a numerosos laboratorios distribuidos por todo el mapa. En la siguiente carta trataré de reflejar la rica variedad que esto representa.

\section{5}

Estoy seguro que tú, que llevas años conviviendo con un fago, eres plenamente consciente del grado de babelización a que ha llegado el lenguaje biológico. Yo empiezo a no entender una buena parte de lo que se comunica en los congresos y reuniones científicas. Tuve que hacer un esfuerzo especial en la última a la que asistí: la V Reunión de Biología Molecular de Plantas, que se celebró hace unos meses en Alicante. Presidía un jurado que debía dirimir unos premios a las mejores comunicaciones y no pude distraerme ni un segundo. Usaré las actas de dicha reunión como guía o apoyo en el safari comentado que sigue. La reunión estuvo coordinada por J. L. Micol, un especialista en biología del desarrollo que se ha interesado recientemente por las plantas.

La idea de esta serie de reuniones fue de Gregorio Nicolás, quien ya empezó en los años 80 a abordar la fisiología vegetal en su aspecto molecular. La primera tuvo lugar en Salamanca en 1991 y fue co-organizada con B. Sabater. Suelen coincidir en estos saraos tanto investigadores vinculados a la Bioquímica y Biología Molecular como militantes de la Fisiología Vegetal. Apenas medio centenar de comunicaciones se presentaron en la I Reunión, mientras que en la V lo han sido casi dos centenares. Unos 70 grupos de investigación estuvieron 
representados y unos 450 nombres figuraban al final de las actas. Por supuesto, la lista no incluye a todos los que forman parte del colectivo nacional, que es de casi un millar de miembros, y entre los laboratorios representados faltaban algunos ciertamente importantes. Finalmente, algunas comunicaciones eran de jóvenes investigadores integrados en grupos extranjeros.

La reunión de Alicante se organizó en diversas sesiones bajo los siguientes conceptos: regulación de la expresión génica; desarrollo; metabolismo; estrés abiótico; estrés biótico; y fitopatógenos. Seguiré ese orden en los breves comentarios que siguen.

Regulación de la expresión génica.-El primer factor de transcripción de plantas fue descrito por J. Paz-Ares hace unos años en el Instituto Max Planck de Colonia (Alemania). Este investigador coordina un consorcio europeo de tres decenas de grupos que ha abordado la descripción sistemática de los factores de transcripción de Arabidopsis. Entre las comunicaciones presentadas, cuatro tenían que ver con transcripción y las restantes estaban relacionadas con transposición, regulación por etileno y procesamiento de RNA en cloroplastos, respectivamente.

Desarrollo.-Los estudios sobre biología del desarrollo vegetal en nuestro país fueron iniciados, después de sendas estancias foráneas, por J. M. Martínez Zapater en Madrid (INIA) y por J. P. Beltrán en Valencia. Se presentaron nueve comunicaciones orales, dos de las cuales correspondían a jóvenes post-doctorales en laboratorios extranjeros.

Metabolismo.-La aplicación de la ingeniería genética a la resolución de los problemas tradicionales de la bioquímica y la fisiología vegetal está dando sus frutos en forma de una variada gama de trabajos sobre enzimas, hormonas, acumulación de sustancias de reserva, metabolitos secundarios, etc. Esta parcela ha de salir muy revitalizada -no sólo en España sino también a escala global- con los recientes avances en genómica. Hay que señalar que el estudio del metabolismo del nitrógeno ha atraído a un alto número de laboratorios que suelen reunirse separadamente y están poco representados en las reuniones de plantas.

Estrés abiótico.-La decana de este tipo de estudios es Monserrat Pagés, quien lleva dos décadas investigando aspectos relevantes de la respuesta de las plantas a la sequía. Merece también mencionarse la aportación al conocimiento de la tolerancia de las plantas a la salinidad que ha supuesto el desembarco verde de especialistas en levaduras interesados en el transporte iónico. Las investigaciones de R. Serrano (IBMCP) son un buen exponente de esta tendencia, muy bien representada en nuestra comunidad científica. 
Estrés biótico.-V. Conejero lleva casi tres décadas interesándose por el estrés causado en las plantas por organismos foráneos y son muchos los laboratorios que en la actualidad se ocupan de las interacciones de las plantas con viroides, virus, bacterias, hongos, nematodos, insectos y otros organismos adversos a los cultivos

Fitopatógenos.-El estudio de los organismos fitopatógenos en sí centra el interés de un número reducido de grupos con proyección internacional. Varios equipos involucrados en el estudio de viroides y virus, así como los muy pocos centrados en bacterias y hongos enlazan con el corpus representado por la Sociedad Española de Fitopatología.

Naturalmente, parte de lo que se hace no se encuadra en los apartados anteriores y, por otra parte, una reseña como ésta tiene que ser deliberadamente injusta, marcada por el sesgo subjetivo del que la escribe y plagada de omisiones debidas a su flaca memoria y a su perversidad. Así debe ser. Como verás, en la carta siguiente acabaré de perderme.

\section{6}

Tenía pensado pasarme unas tardes visitando el Science Citation Index, ese espejo de Narciso que tanto frecuentan algunos. Las premuras con que escribo estas líneas no me permiten cumplir dicho plan, por lo que no podré revestir mis conclusiones de la aparente objetividad de lo falsamente científico. En esta última carta pretendo expresarte mis ideas extraviadas sobre la apreciación de la ciencia por los propios científicos y resumirte mis opiniones globales sobre el presente y futuro de la investigación botánica en nuestro país.

Todavía recuerdo cuando la mayor parte de la ciencia que se hacía en España se publicaba en revistas institucionales españolas. Trabajos excelentes compartían el espacio impreso con aportaciones triviales y la comunidad científica - tanto la nacional como la internacionaltenía que apañarse para separar el grano de la paja. Luego empezó a imponerse la publicación en lengua inglesa, sin importar mucho la naturaleza de la revista donde se hiciera.

Así por ejemplo, en la rápida expansión universitaria de los años 70 , uno de los decanos-comisarios que se reclutaban al crear nuevas facultades se ufanaba de haber nombrado encargado de cátedra a alguien que tenía «tres trabajos en inglés». Luego resultó que ninguno de esos trabajos tenían que ver con la disciplina correspondiente. Ese mismo decano impidió a los primeros profesores que llegaron al centro 
subscribirse a las revistas científicas de sus respectivas especialidades porque él ya se había gastado el presupuesto en comprar «todo lo de Harvard». Al cabo de unos meses llegaron unas cajas que contenían preciosas ediciones de Sófocles, Esquilo, y otros autores clásicos publicadas en inglés por Harvard University Press.

Pronto se pasó a valorar sólo lo publicado en revistas contenidas en el Current Contents, esa biblioteca para pobres que tantos servicios nos prestó. En esa época yo ayudé a colegas de las más diversas disciplinas a poner sus trabajos científicos en inglés, una tarea no muy distinta de la del actor, por lo que tiene de asumir personalidades distintas a la propia. Esto me resultaba muy gratificante. Mi mayor éxito fue con un trabajo sobre los mitos religiosos en la pintura rupestre: su autor proclamó públicamente que la versión inglesa era muy superior a la española.

Yo le solía dar a Eladio algunos de mis manuscritos para que me hiciera sugerencias y él también me pasaba a veces los suyos con el mismo fin. Tú no lo hacías, Margarita, pero, en cualquier caso, nunca hubiera podido estar a la altura de tu ritmo de publicación que era, ya entonces, trepidante. Eladio solía hacerme bastante caso, lo que me resultaba de gran estímulo. En particular, incluyó varias sugerencias mías - una de ellas tachada luego por Ochoa, que la consideró demasiado indiscreta- en el ensayo que escribió por invitación de Garfield cuando el trabajo sobre la electroforesis con SDS fue seleccionado como citation classic.

Antes de la ocasión referida, el nombre de Eladio ya había aparecido en una de esas recopilaciones que publicaba Garfield en el Current Contents. Según creo recordar, su nombre era el único domiciliado en España que figuraba en una lista de los mil autores más citados de cualquier disciplina en todo el mundo durante una década. Su trabajo más popular era, en efecto, el ya aludido, pero el resto de sus trabajos también habían recibido un alto número de citas. Resulta obvio decir que la obra de Eladio era ya mucho más importante que su idea feliz y oportuna sobre la electroforesis y que él mismo suponía mucho más que sus publicaciones tomadas de una en una. Eladio era sobre todo su creatividad al plantear grandes avenidas que transitar, era su vocación de abordar problemas difíciles y relevantes, junto a su disponibilidad para correr los riesgos consiguientes, era la congruencia de toda su obra y era su visión del futuro. El número de veces que sus trabajos fueron citados no nos cuenta en absoluto quien era Eladio, por digno de ser tenido en cuenta que sea este dato numérico. 


\section{Cartas botánicas en recuerdo de Eladio Viñuela}

Todos los cambiantes criterios de calidad científica han sido extraordinariamente útiles para que el país pudiera empezar a aproximarse a lo que tiene que ser. En la sabia aplicación de estos criterios ha estado en parte el secreto de nuestro progreso. Sin embargo, ha llegado la hora de no confundir el recipiente con el contenido o la calidad de la obra con el número de espectadores. El índice de audiencia debe ser tenido en cuenta, pero usado sin mesura tiene consecuencias deletéreas que todos podemos comprobar con sólo apretar un botón. Alguien con criterio tiene que examinar el contenido de las obras de Corín Tellado, de Valente, de Pérez Reverte o de Joyce si quiere saber lo que significan para la literatura y para la sociedad. Cuando en España ha dejado de crecer exponencialmente la actividad investigadora, va siendo hora de primar el juicio maduro sobre la pueril y alocada aplicación de criterios falsamente cuantitativos. Valente y Corin Tellado pertenecen a "universos de citación distintos», los conjuntos de sus lectores quiero creer que no se solapan, su valor literario y social nada tiene que ver con cuántos lean o citen a cada uno.

Como sabes, Margarita, hace unos meses se sometieron unas decenas de nombres españoles a evaluación por parte de varios cientos de sus colegas europeos. Las conclusiones que pude sacar de los resultados de esa encuesta-votación son en esencia tres: a) no estamos realmente donde creemos estar; b) hay que pelear duramente por que nos reconozcan donde estamos realmente; c) la valoración de la obra científica implica algo más que constatar en qué revistas se publicó o cuantas citas acumuló.

Si algún malicioso piensa que hago estas reflexiones por razones interesadas, debo decir que los departamentos que se dedican a lo vegetal en las universidades politécnicas salen en cabeza de la investigación biomédica universitaria en un reciente estudio bibliométrico publicado en el Boletín de la SEBBM. He hecho la anterior digresión porque debo fundamentar ahora una mala noticia, después de haber dado la buena nueva de que la genética molecular de plantas ha hecho progresos notables y en la actualidad goza de buena salud. La mala noticia es que vamos a perder de nuevo el tren de un momento a otro. Las alusiones a la obra de Eladio no las he incluido sólo porque estas líneas estén escritas en su homenaje sino porque las cualidades que él encarnó resultan esenciales para enfrentar el reto que acabo de enunciar.

En el ámbito botánico, como en otras vertientes de los estudios biológicos, se ha pasado bruscamente de una investigación guiada por las hipótesis a una concepción de dicha actividad dominada por las 


\section{Francisco García Olmedo}

grandes plataformas de generación de datos. Mientras está ocurriendo este cambio radical, la administración científica española está distraída maquillando las estadísticas y parece carecer en su seno de una visión certera de los cambios que están ocurriendo y de cómo adaptarnos a ellos. La comunidad científica vive una fragmentación considerable - la más extrema de Europa, con un tamaño medio de los grupos realmente ridículo- que está condicionada por el marco legal y estructural, así como por el frenazo que nuestro desarrollo científico ha sufrido en los últimos años. No sólo no encuentran puesto de trabajo científicos ya plenamente formados sino que la alarma ha cundido $y$, ante la inexistencia de una carrera científica, cada vez menos jóvenes eligen dedicarse a la investigación.

En esta coyuntura resulta difícil emprender trayectorias a largo plazo que, por su ambición, comporten un riesgo cierto de fracasar y que requieran infraestructuras modernas, así como equipos humanos grandes y diversificados. El futuro requiere que nos integremos en foros de los que estamos siendo excluidos rápidamente. Los nuevos tiempos requieren jóvenes que, como Eladio en su día, tengan visión de futuro, espíritu de lucha, ambición y disposición para el riesgo, que no sólo sean buenos secundadores del juego que crean otros sino que sean ellos mismos creadores de juego capaces de encabezar iniciativas internacionales. La genética molecular de plantas se encuentra claramente en esta situación y las circunstancias no favorecen los cambios necesarios.

En 1852, Franz Unger, que era profesor de Mendel, publicó en la prensa vienesa, de forma anónima, diecisiete "Cartas Botánicas» en las que exponía ideas tan heterodoxas que, una vez identificado como autor por el director del periódico oficial católico, hicieron peligrar su puesto y le valieron una feroz campaña en contra, en la que fue acusado de agnóstico, socialista y pagano. Espero que, aunque se presenten bajo el mismo título, estas modestas líneas no suscitarán las mismas iras que las que escribió Unger y que, en cambio, serán tomadas con el mismo humor con que han sido escritas. A Eladio le hubiera gustado que hubiera habido tomate. 